\title{
EXAMINATION INTO THE EFFECTS OF JOB SATISFACTION ON SALESPERSON DEVIANCE: THE MODERATING ROLE OF CUSTOMER ORIENTATION
}

\author{
Joseph LO IACONO ${ }^{1}$, Scott K. WEAVEN ${ }^{2}$, Deborah GRIFFIN ${ }^{3}$ \\ Department of Marketing, Griffith University, Parklands Drive, Southport Qld 4215, Australia \\ E-mails: ${ }^{1}$.loiacono@griffith.edu.au (correspondingauthor); ${ }^{2}$ s.weaven@griffith.edu.au; \\ 32deborah.griffin@griffith.edu.au
}

Received 27 August 2014; accepted 27 April 2015

\begin{abstract}
Salesperson deviance represents a significant cost to organizations throughout the world. This paper addresses a gap in the literature by examining all three dimensions of salesperson deviance (i.e., organizational deviance, interpersonal deviance and customer-directed deviance) and the moderating role of customer orientation. More specifically and using a sales personnel sample, this research extends current understanding of deviant behavior in two key areas. Our findings show (1) a negative relationship between job satisfaction and each dimension of salesperson deviance, and (2) customer orientation moderates the relationship between job satisfaction and salesperson deviance. Thus, we present a more holistic view of salesperson deviance and, in practical terms, confirm that organizational stakeholders should proactively manage the job satisfaction together with the customer orientation of their sales staff in order to avoid and/or minimize deviant behaviors.
\end{abstract}

Keywords: salesperson deviance, organizational deviance, interpersonal deviance, customer-directed deviance, customer orientation, job satisfaction.

JEL Classification: M1, M12.

\section{Introduction}

Salesperson deviance is a pervasive issue for many organizations (Chawla 2014; Swimberghe et al. 2014; Yoo, Frankwick 2013; Yoo et al. 2014). For instance, 40 percent of sales representatives admit to engaging in deviant behaviors (Darrat et al. 2010) with some estimates suggesting this figure extends beyond 85 percent (Harris, Ogbonna 2006). Somewhat concerningly, an alarming 66 percent of sales personnel do not believe deviant behaviors would result in consequence (Darret et al. 2010). Thus, workplace deviance is a widespread organizational phenomenon. However, while scholars acknowledge these aberrant organizational behaviors damage service delivery and firm reputation (Alias, Rasdi 2015; Bennett, Robinson 2000; Harris, Ogbonna 2006), the relationship between salesperson deviance and customer outcomes have, to date, received little attention. 
Extant deviance research supports that increases in ones job satisfaction reduces their deviance. For example, adopting an attitudinal theoretical lens, Mulki et al. (2006) find negative sentiments held towards one's job foster negative workplace behaviors. Similarly, Mount et al. (2006) and Alias et al. (2013) support job satisfaction, reduced deviance towards their coworkers and the organization. However, the relationship between job satisfaction and deviance has not yet been examined within a sales and marketing context and consequently, the effects of salesperson deviance on customers remains largely unexplored (Darrat et al. 2010).

Thus, the primary goal of this study is to examine the impact of employee satisfaction on salesperson deviance directed towards the organization, fellow employees and customers. Furthermore, little if any research has explored direct or indirect effects of an individual's customer orientation on resultant deviant behavior. To this end, we investigate the moderating role of customer orientation on the relationship between job satisfaction and salesperson deviance. We believe that this examination extends conventional wisdom concerning the relationship between job satisfaction and salesperson deviance through examining the indirect effects of an individual's customer orientation.

\section{Literature review}

\subsection{Salesperson deviance}

Salesperson deviance is voluntary behavior perpetuated by salespeople that violates organizational norms and, by doing so, threatens the well-being of the organization, its' employees, customers, prospects or, a combination of all three (Robinson, Bennett 1995; Darrat et al. 2010). Robinson and Bennett (1995) categorized deviant behavior into acts directed towards the organization (i.e., organizational deviance) and fellow staff (i.e., interpersonal deviance) and has since appeared in a range of organizational contexts (Darrat et al. 2010). More recently, Darrat et al. (2010) conceptualized a third dimension; customer-directed deviance. As sales personnel regularly interact with customers, they provide context for closer examination in all three dimensions of deviant behavior. In line with the approach taken by Robinson and Bennett (1995) and Mount et al. (2006) we treat each dimension of salesperson deviance (i.e., organizational, interpersonal and customer-directed deviance) as an individual construct in order to best understand the nature of relationships examined in this study.

Organizational deviance is a salesperson's deviant behavior directed towards their working organization (Robinson, Bennett 1995). Instances range from minor occurrences like absenteeism or arriving late to serious offences such as damaging company equipment and improper usage of company resources (Robinson, Bennett 1995). Comparatively, interpersonal deviance is directed towards a salesperson's fellow employees, and also fluctuates on a continuum from minor acts like criticizing co-workers and gossiping about fellow staff and, to more serious incidents like verbally abusing and sexually harassing other staff (Robinson, Bennett 1995). Further, consistent with Darrat et al. (2010) we refer to a salesperson's deviant behavior directed towards their customers or prospects as customer-directed deviance. These deviant activities include knowingly selling defective products, coercing consumers to complete a purchase; abusing, cursing or discriminating customers or prospects (Darrat et al. 2010). 
Research documents salespeople engage in organizational, interpersonal and customerdirected deviance for a range of reasons, from bureaucratic influences (Jelinek, Ahearne 2006); trait competitiveness; working longer hours (Jelinek, Ahearne 2010) and work and family conflict (Darrat et al. 2010). However, the influence of job satisfaction is of particular interest due to the established relationship with numerous positive outcomes (e.g., developed employee productivity, customer satisfaction, and profitability) (Heskett, Schlesinger 1994). However, despite previous examination of job satisfaction's impact on organizational and interpersonal deviance (e.g., Mount et al. 2006), the relationship with customer-directed deviance has been overlooked. Therefore, this research is the first to re-affirm an understanding of job satisfaction's effect on organizational and interpersonal deviance, and then, explore whether this relationship extends to customer-directed deviance.

\subsection{Job satisfaction}

Job satisfaction refers to the "pleasurable emotional state" a person feels as the result of the self-appraisal of one's job (Locke 1969: 316). Several scholars argue job satisfaction reduces deviant behavior (Alias et al. 2013; Fatima et al. 2012; Judge et al. 1997; Mount et al. 2006). For instance, using adaption theory, Judge et al. (1997) contends deviance is a form of survival when working in a dissatisfying job. Similarly, Mount et al. (2006) and Alias et al. (2013) support satisfaction reduces deviant behaviors directed towards the organization and co-workers, and Fatima et al. (2012) also report a negative association between job satisfaction and counterproductive work behaviors. In relation to organizational and interpersonal deviance, Mount et al. (2006) report negative relationships between job satisfaction and organizational and interpersonal deviance. Although these relationships are established in the literature, prior to testing moderating effects, it is necessary to first examine direct relationships. Thus, we propose:

H1a: Job satisfaction has a significant negative effect on organizational deviance.

H1b: Job satisfaction has a significant negative effect on interpersonal deviance.

To our knowledge the effect of job satisfaction on customer-directed deviance has not been examined, however, we suspect a salesperson's job satisfaction will reduce deviant behaviors directed towards customers. Bennett and Robinson (2000: 349) suggest although deviant behaviors fall into clusters, each dimension is "similar to each other, [and] share similar antecedents, and thus, may be functional substitutes for one another". Therefore, sales personnel who perceive untoward treatment are more likely to feel dissatisfied and spiteful (Mount et al. 2006). Thus, based on the norm of reciprocity, salespeople feeling this way may not only respond with deviant behaviors towards the organization and fellow employees, but also reciprocate to customers (Hulin 1991). In contrast, the reciprocal behaviors of happy and satisfied sales staff may avoid adversely related behaviors (Organ et al. 2006). Moreover, deviance can also be viewed as a form of withdrawal, where dissatisfied salespeople may reduce their effort in their work. In view of this, the well-established link between job satisfaction and withdrawal provides support for the relationship between employee satisfaction and customer-directed deviance (Hulin 1991). On this basis, we hypothesize: 
H1c: Job satisfaction has a significant negative effect on customer-directed deviance.

Although deviance is extensively researched, the majority of studies examine deviance as a reaction to specific experiences. However, in order to gain a better understanding of more complex relationships, Bennett and Robinson (2003) suggest investigation of potential moderators, and more specifically, individual differences of employees. Following Bennett and Robinson's (2003) suggestion, a growing number of studies explore the effects of individual employee differences on deviance (Jelinek, Ahearne 2010), however, we believe a gap exists with regard to a salesperson's customer orientation. This oversight is highly relevant granted salespeople link organizations to customers and their customer-orientated traits are an important aspect of their job (Churchill et al. 1974). Thus, as depicted in the conceptual model (see Fig. 1) we examine the moderating role of customer orientation on job satisfactions effect on organizational, interpersonal and customer-directed deviance.

\subsection{Customer orientation}

Customer orientation is an individual difference construct referring to a salesperson's "tendency or predisposition to meet customer needs in an on-the job context" (Brown et al. 2002: 111). Within a sales context, customers typically need to feel secure in their purchase, and as individual and organizational performance is largely dependent on understanding customer needs, a salesperson's customer orientation impacts relationships developed with customers (Thomas et al. 2001).

Despite a lack of research investigating linkages between customer orientation and salesperson deviance, theoretical and empirical research supports this relationship. Specifically, customer orientated salespeople engage in behaviors designed to develop long-term customer satisfaction (Saxe, Weitz 1982). Therefore, one can conjecture salespeople possessing these traits are more likely to place greater effort towards treating their customers' well, and thus, avoid behaviors that promote customer dissatisfaction. Moreover, we suggest that customer-orientated salespeople should exhibit higher concern for others, and thus, be less likely to direct deviance towards customers, the organization or co-workers. Alternatively, salespeople possessing low customer orientation often hold high concerns for themselves, and consequently, may indulge in deviant behavior in pursuing their own agenda (Saxe, Weitz 1982). With respect to job satisfaction, satisfied salespeople are more often customer orientated. In fact, Hoffman and Ingram (1992) provide evidence of a correlation between one's job satisfaction and customer orientation, where intrinsic satisfaction (e.g., satisfied with dimensions of work, co-workers, supervision and promotion) was significantly related to customer orientation, whilst extrinsic satisfaction (e.g., satisfaction with pay) was not. This finding is consistent with the basic tenets of the service profit chain, which specifies that organization's seeking to satisfy customer needs and wants must first satisfy employees (Heskett, Shlesinger 1994).

Whilst salespeople may recognize the long-term benefit of being customer oriented, they are often faced with budgetary requirements in the short-term (Saxe, Weitz 1982). For instance, sales personnel under pressure to reach their sales targets may forego focus- 
ing on customer orientation, and instead engage in deviant behaviors to achieve these budgets. However, should these salespeople be satisfied in their jobs, they may be more inclined to act in the long-term interests of the organization, co-workers and customers. That is, satisfied salespeople may not be customer orientated, or dissatisfied salespeople may possess customer orientation. Thus, a salesperson's customer orientation may alter the nature of the relationship between job satisfaction and deviant behavior.

In support of these arguments, the theory of self-determination suggests (regardless of activities an organization engages in designed to extrinsically motivate their workforce) salespeople could advocate a personal customer orientation even if they are dissatisfied with other aspects of the job (Deci, Ryan 2002). Moreover, we believe customer orientation can be viewed as an inherited trait; therefore, whilst salespeople may be dissatisfied with their job, they may or may not possess this trait, ultimately affecting the impact of the relationship between satisfaction and deviant behavior. Thus, we hypothesize:

H2a: Customer orientation moderates the effect of job satisfaction on organizational deviance (such that greater customer orientation reduces the effect of job satisfaction and lesser customer orientation increases the effect of job satisfaction).

H2b: Customer orientation moderates the effect of job satisfaction on interpersonal deviance (such that greater customer orientation reduces the effect of job satisfaction and lesser customer orientation increases the effect of job satisfaction).

H2c: Customer orientation moderates the effect of job satisfaction on customer-directed deviance (such that greater customer orientation reduces the effect of job satisfaction and lesser customer orientation increases the effect of job satisfaction).

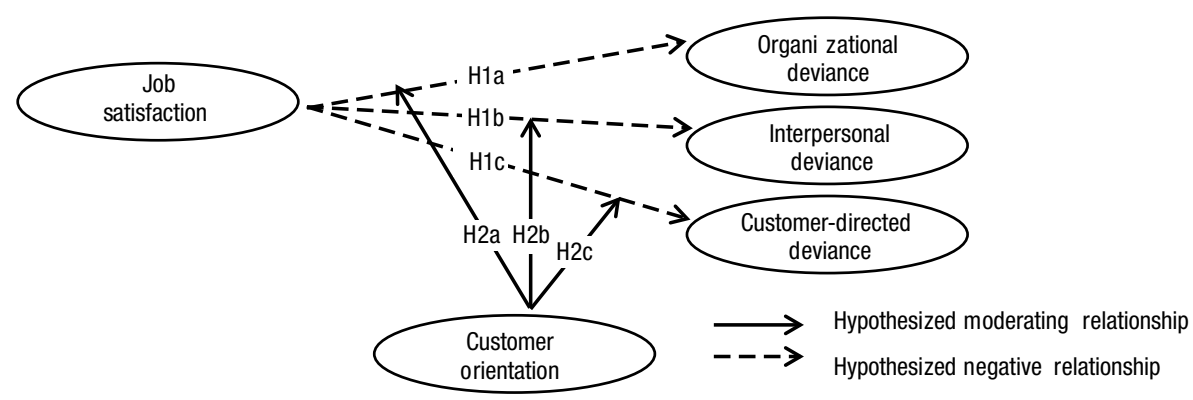

Fig. 1. Hypothesized model

\section{Methodology}

\subsection{Sample}

In 2013, a third-party market research agency recruited respondents via email, inviting participation to an online survey. The sample consisted of 244 full-time sales employees working within Australia's service sector, 168 males and 74 females. More than two thirds were aged 25 to $44(71 \%)$ and just under half reported working as an intermediate level sales employee (46\%), closely followed by sales management roles $(38 \%)$. A 
substantial proportion of respondents (66\%) reported earning an annual income between \$35 000 and \$74 999 and tenure was almost evenly spread across each category, with the highest percentage of respondents (33\%) reporting 3 to 5 years. Fully, 54 percent reported employment in a large organization (i.e., $>200$ employees). The findings support respondent's work across a spread of service industries, with 32 percent employed in retail. Further, the largest proportion of respondents attained high school or equivalent qualifications (41\%), followed by a diploma (25\%) and other qualifications including bachelor's or master's degree (34\%).

\subsection{Survey measures}

All scale items were drawn from existing measures. Organizational deviance was measured with six items developed by Darrat et al. (2010). Interpersonal deviance was measured with eight items from Darrat et al. (2010), two of which were adapted to appeal to an Australian sample. Six items measured customer-directed deviance again sourced from Darrat et al. (2010), two of which adapted to a service industry context. Job satisfaction was measured with four items used verbatim from Hartline and Ferrell (1996) and six items from Brown et al. (2002) measured customer orientation. Scale items were measured on a six-point Likert scale on the basis that respondents tend to answer neutral on sensitive work issues (McCain et al. 2010). With this in mind, an even Likert scale would force respondents to make a decision (Malhotra 2010). Deviance items were measured based on the degree of participation from never to always, job satisfaction was measured on the level of satisfaction from extremely dissatisfied to extremely satisfied and customer orientation was measured on the level of agreement from strongly disagree to strongly agree.

\subsection{Procedure}

Subjects were screened to include full-time sales representatives within the services industry. Only full-time employees were surveyed, in order to minimize potential for extraneous effects (associated with employment status e.g., full-time, part-time, casual, etc.) contaminating the findings. Respondents not meeting the criteria were unable to proceed to the online instrument. On this basis, the sampling technique was purposive in nature as respondents' eligibility was contingent upon qualifying on dimensions of sales involvement and employment status (Teddlie, Yu 2007).

\section{Results}

Data analysis followed a two-phase process consisting of preliminary analyses and hypotheses testing. The purpose of the preliminary analysis phase was to establish the integrity of the data via principle components factor analysis with oblimin rotation and reliability analysis.

\subsection{Preliminary analysis}

After obtaining descriptive statistics of the sample, two tests were conducted to assess the reliability and validity of each construct. The first was a principle components factor analysis with oblimin rotation and second, a reliability test to examine the internal 
consistency of the indictors (Pallant 2010). The means, standard deviations and intercorrelations of each construct are presented in Table 1. All factor loadings and reliabilities met acceptable benchmark values presented in Table 2 (Hair et al. 2006). Prior to testing the hypotheses, the items of each construct were summed to produce a composite measure of each construct.

Table 1. Descriptive statistics and variables intercorrelations

\begin{tabular}{|c|c|c|c|c|c|c|c|}
\hline & & Standard & & & & & \\
\hline Variables & Mean & deviation & 1 & 2 & 3 & 4 & 5 \\
\hline Customer orientation & 4.75 & .91 & 1 & & & & \\
\hline Job satisfaction & 4.32 & .93 & $.544 * *$ & 1 & 1 & & \\
\hline Organizational deviance & 1.80 & .74 & $-.255^{* *}$ & $-.334 * *$ & & & \\
\hline Interpersonal deviance & 1.52 & .67 & $-.241 * *$ & $-.172 * *$ & $.581 * *$ & 1 & \\
\hline Customer-directed deviance & 1.50 & .67 & $-.156^{*}$ & $-.156^{*}$ & $.574 * *$ & $.710 * *$ & 1 \\
\hline
\end{tabular}

Notes: $N=244,{ }^{*} p<0.05 ; * * p<0.01$.

\subsection{Hypotheses testing}

Using regression analysis, we found job satisfaction as a significant predictor of organizational deviance $(\mathrm{sig}=.000, \beta=-.334, \mathrm{t}=-5.510)$, interpersonal deviance $(\mathrm{sig}=$ $.007, \beta=-.172, \mathrm{t}=-2.714)$ and customer-directed deviance $(\mathrm{sig}=-.015, \beta=-.156$, $\mathrm{t}=-2.458$ ). To test the moderating role of customer orientation, we followed the analytic procedure outlined by Aiken and West (1991) involving a multiplicative interaction term, and a simple slopes analysis. As recommended by Morris et al. (1986) we first centered both the independent and moderator variable in an attempt to reduce multicollinearity. The results of moderated regression showed customer orientation moderated the relationship between job satisfaction and organizational deviance (sig = $.001, \beta=-.224, \mathrm{t}=-3.404)$, interpersonal deviance $(\mathrm{sig}=.000, \beta=-.232, \mathrm{t}=-3.705)$ and customer-directed deviance $(\mathrm{sig}=.004, \beta=-.195, \mathrm{t}=-2.872)$. Using simple slope analyses, we found the relationship between job satisfaction and each dimension of salesperson deviance strongest for respondents with high customer orientation as evidenced in Figures 2-4. Furthermore, these figures indicate that customer orientation had the greatest effect on the negative relationship between interpersonal deviance and job satisfaction.

\section{Implications, limitations and future research}

\subsection{Theoretical implications}

This research extends our current understanding of salesperson deviance. The results clearly support job satisfaction and customer orientation play a role in reducing deviant behaviors. Firstly, we replicated prior research identifying a negative relationship between job satisfaction and organizational and interpersonal deviance (H1a, H1b). 
Table 2. Preliminary analysis of constructs

\begin{tabular}{|c|c|c|c|c|}
\hline Construct & Item & SL & CR & VE \\
\hline $\begin{array}{l}\text { Organizational } \\
\text { deviance }\end{array}$ & $\begin{array}{l}\text { I have spent too much time fantasizing or daydreaming } \\
\text { instead of working } \\
\text { I have neglected to follow my supervisor's instructions } \\
\text { I have put little effort into my work } \\
\text { I have arrived to work and/or sales meeting without } \\
\text { permission } \\
\text { I have refused to share relevant customer information } \\
\text { with my organization } \\
\text { I have "worked from home" but did not do much at all }\end{array}$ & $\begin{array}{l}.83 \\
.80 \\
.79\end{array}$ & .82 & $53.67 \%$ \\
\hline $\begin{array}{l}\text { Interpersonal } \\
\text { deviance }\end{array}$ & $\begin{array}{l}\text { I have said something hurtful to someone at work } \\
\text { I have verbally-abused a co-worker at work } \\
\text { I have acted rudely toward someone at work } \\
\text { I have publicly embarrassed someone at work } \\
\text { I have made an ethnic, religious or racial remark at work } \\
\text { I have played a mean prank on someone at work } \\
\text { I have made a sale inside another co-worker's territory } \\
\text { I have deferred an undesirable customer to another } \\
\text { worker }\end{array}$ & $\begin{array}{l}.82 \\
.81 \\
.78 \\
.77 \\
.74 \\
.71 \\
.67\end{array}$ & .88 & $55.90 \%$ \\
\hline $\begin{array}{l}\text { Customer- } \\
\text { directed } \\
\text { deviance }\end{array}$ & $\begin{array}{l}\text { I have provided poor service to a customer based } \\
\text { on his/her ability to pay } \\
\text { I have used coercion on a customer in order to make } \\
\text { a sale } \\
\text { I have knowingly provided sub-standard service } \\
\text { I have used deception to make a sale } \\
\text { I have made an ethnic, religious or racial remark to } \\
\text { a customer } \\
\text { I have intentionally delayed an order to punish } \\
\text { a customer }\end{array}$ & $\begin{array}{l}.76 \\
.77 \\
.74 \\
.72\end{array}$ & .82 & $54.02 \%$ \\
\hline $\begin{array}{l}\text { Job } \\
\text { satisfaction }\end{array}$ & $\begin{array}{l}\text { Your supervisor(s) } \\
\text { Your fellow workers } \\
\text { Your overall job } \\
\text { Your organization's customers }\end{array}$ & $\begin{array}{l}.85 \\
.84 \\
.83 \\
.73\end{array}$ & .83 & $66.37 \%$ \\
\hline $\begin{array}{l}\text { Customer } \\
\text { orientation }\end{array}$ & $\begin{array}{l}\text { I enjoy responding quickly to my customers' requests } \\
\text { I really enjoy serving my customers } \\
\text { I get satisfaction from making my customers happy } \\
\text { It comes naturally to have empathy for customers } \\
\text { I find it easy to smile at each of my customers } \\
\text { I enjoy remembering my customers' names }\end{array}$ & $\begin{array}{l}.91 \\
.90 \\
.89 \\
.89 \\
.85 \\
.84\end{array}$ & .78 & $77.24 \%$ \\
\hline
\end{tabular}

SL: standardized loadings; CR: composite reliability; VE: variance explained. 


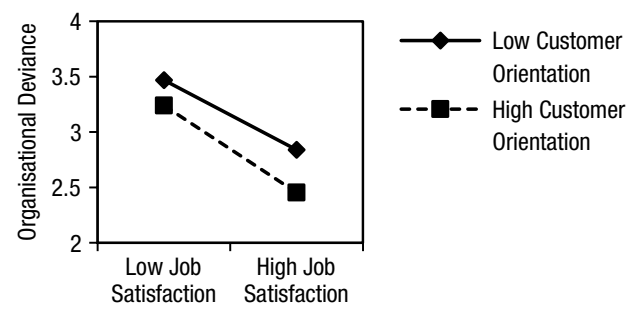

Fig. 2. Moderating role of customer orientation on job satisfaction and organizational deviance

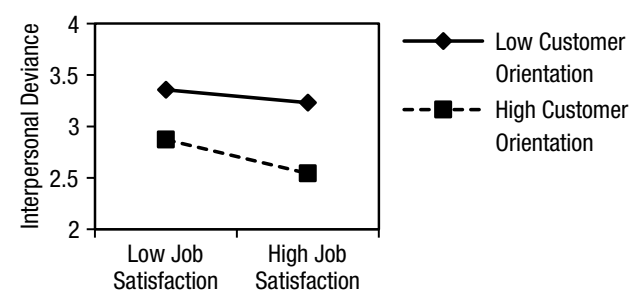

Fig. 3. Moderating role of customer orientation on job satisfaction and interpersonal deviance

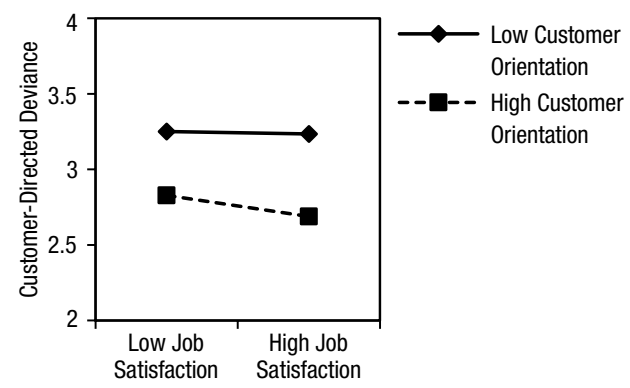

Fig. 4. Moderating role of customer orientation on job satisfaction and customer-directed deviance

However, a key contribution of this study is in finding job satisfaction also reduces deviance directed towards customers (H1c). This finding confirms earlier assertions by Bennett and Robinson (2000) that deviance dimensions may share similar antecedents. The negative impact job satisfaction has on customer-directed deviance, implies sales managers must maintain high levels of job satisfaction in their sales force. Through such action, not only will sales managers reduce the likelihood of organizational and interpersonal deviance, but they will also diminish issues associated with customer-directed deviance such as customer complaints (Fornell, Wernerfelt 1987). These results suggest satisfied salespeople are productive and thus, contribute to performance outcomes by being less likely to engage in deviant behaviors.

As predicted, customer orientation magnifies the effect of job satisfaction on all dimensions of salesperson deviance $(\mathrm{H} 2 \mathrm{a}-\mathrm{H} 2 \mathrm{c})$. This finding suggests customer-orientated employees tend to maximize their efforts towards treating customers well and thus avoid behaviors dissatisfying their customers and negatively impacting their organization and co-workers. Moreover, our findings indicate a salesperson's individual characteristics, like their consumer orientation can play a focal role in reducing deviant behavior per se. Further, our results imply satisfied employees may not always be customer-orientated and vice versa. Given this, one may question whether the central premise of the profit chain is always the case and hence, we encourage further research in this area. 


\subsection{Managerial implications}

Our findings provide new information that may be beneficial for a number of key organizational stakeholders, on how to better manage salesperson deviance. Specifically, this research contributes an understanding of customer-directed deviance in relation to other constructs (i.e., job satisfaction and customer orientation). For instance, as the service an organization provides underscores resultant performance outcomes, developing a greater understanding of behaviors that may impair these encounters is critically important. Therefore, with this knowledge we believe that sales managers may be able to identify the causes of customer-directed deviance and determine how to reduce these behaviors within their organizations. A further implication is a better understanding of job satisfaction's influence on all types of deviance and an understanding of how customer orientation magnifies the effect of these relationships. Thus, organizations experiencing deviant behavior (or wishing to prevent its occurrence) may seek to promote greater job satisfaction in their sales teams whilst also managing the customer orientation of potential and incumbent salespeople.

Our findings relating to the effect of customer orientation has clear practical implications. As discussed previously, the customer orientation of salespeople is particularly essential as these personnel link the organization and customers together; thus, satisfying the needs of customers will contribute to customer satisfaction, commitment and retention (Henning-Thurau 2004). We suggest sales managers manage customer orientation by screening potential and current sales personnel to ascertain if they possess a positive orientation towards customers. Alternatively, these individuals that possess a lower customer orientation may be provided with specific training and engagement programs designed to build levels of customer orientation and thus, enhance their satisfaction in their current job roles. Moreover, our results accord with recent work by Korschun et al. (2014) suggesting that customer identification of frontline employees is inextricably linked with customer orientation and service outcomes. However, successful customer orientation outcomes are predicated on the distinction between organizational identification and customer identification, which needs to be made within the context of defined job roles and performance criteria. With this in mind, our research provides a solid framework for examining the role of customer- and organizational-identification and the potential for deviant work-related behaviors.

\subsection{Limitations and future research}

Although our study presents significant contributions, it is not without limitations. First, there is a possibility of measurement error given survey research requires respondents to accurately report their level of agreement, satisfaction and participation with a survey item. However, data analysis supports all relationships authenticating measurement error was not an issue, substantiated through reliability and validity checks surpassing acceptable benchmark values. Second, the generalizability of this research's findings outside Australia may be problematic granted data collection was only facilitated within this region. Nevertheless, as data was collected from a spread of industries, and given the similarity between the Australian services sector and that of the other countries (e.g., the USA and the UK), the results of this study could be extended to a broader context. 
The organizational behavior literature is replete with studies examining a range of antecedents, moderators and mediators of deviant behavior in the workplace. However, in spite of this, the effect of salesperson deviance on customer outcomes has only appeared recently in sales literature (Darrat et al. 2010). Therefore, we commend to future scholars in this domain explore whether specific antecedents have relationships with customer-directed deviance that are not be present with either organizational or interpersonal deviance. In particular, the reward structures of salespeople may prove an interesting line of inquiry, as salespeople whose remuneration is commission-based may rely on over-promising or lying to customers so as to reach their sales goals. Although previous studies support that commission-based sales personnel engage in some deviant acts directed towards the organization such as falsifying expense accounts, it would be interesting to ascertain whether these salespeople also engage in interpersonal deviance, as opposed to salaried salespeople (Litzky et al. 2006).

Future research may also explore whether the conceptualized model extends across cultures different to that of Australia. Of particular interest are the similarities and differences of the model amongst individualistic cultures (e.g., USA, Canada, and the UK) and that of collectivist cultures (e.g., Japan, China, and India). Collectivist cultures are founded on high respect for authority (Hofstede 1984), suggesting that dissatisfied sales personnel within these nations may not necessarily retaliate via engagement in deviant behaviors. Moreover, Huff and Kelley (2005) report lower levels of customer orientation than within individualistic cultures. Thus, testing our model in different country contexts appears a logical and interesting extension for deviance researchers.

Finally, statistics scholars (e.g., Hair et al. 2006) recognize that respondents tend to answer by selecting extremes on likert scales. Therefore, we recommend researchers explore the deviance phenomena, within a field experiment to see if the results produced in this study are replicated with differing methodologies.

\section{Conclusions}

Salesperson deviance is a problematic issue that significantly impacts' organizations, their workforce and their customers. Although extant literature has clearly established a relationship between job satisfaction and deviance directed towards the organization (i.e., organizational deviance) and one's colleagues (interpersonal deviance), the relationship between job satisfaction and customer-directed deviance and role of customer orientation has not, to date, been examined within the literature. Therefore, we sought to investigate employee satisfaction and customer orientation in relation to all three dimensions of salesperson deviance. As shown by the findings, job satisfaction was found to reduce each dimension of salesperson deviance and furthermore, sales personnel possessing a customer-orientated trait amplified the nature of these relationships. Given that deviant behavior may incur significant costs that extend beyond financial considerations (e.g., customer complaints, firm reputation, etc.), this research provides a resource for key organizational stakeholders to reduce these problematic behaviors amongst their salesforce through not only engaging job satisfaction of employees but 
also through the identification and utilization of their customer orientation. Although the proposed model is employed in the context of sales organizations, it provides a comprehensive framework that can be applied in examining decision making across other types of organizational arrangements.

\section{References}

Aiken, L. S.; West, S. G. 1991. Multiple regression: testing and interpreting interactions. Newbury Park, CA: Sage.

Alias, M.; Rasdi, R. M. 2015. Organizational predictors of workplace deviance among support staff, Procedia - Social and Behavioral Sciences 172(1): 126-133. http://dx.doi.org/10.10.1016/j. sbspro.2015.01.345

Alias, M.; Rasdi, R. M.; Ismail, M.; Samah, B. A. 2013. Influences of individual-related factors and job satisfaction on workplace deviant behaviour among support personnel in Malaysian public service organizations, Human Resource Development International 16(5): 538-557.

http://dx.doi.org/10.1080/13678868.2013.812315

Bennett, R. J.; Robinson, S. L. 2000. Development of a measure of workplace deviance, Journal of Applied Psychology 85(3): 349-360. http://dx.doi.org/10.1037/0021-9010.85.3.349

Bennett, R. J.; Robinson, S. L. 2003. The past, present and future of workplace deviance research, in J. Greenberg (Eds.). Organizational behavior: the state of the science, Chapter 7. Mahwah, NJ: Erlbaum.

Brown, T. J.; Mowen, J. C.; Donavan, D.T.; Licata, J. W. 2002. The customer orientation of service workers: personality trait effects on self-and supervisor performance ratings, Journal of Marketing Research 39(1): 110-119. http://dx.doi.org/10.1509/jmkr.39.1.110.18928

Chawla, V. 2014. The effect of workplace spirituality on salespeople's organisational deviant behaviours: research propositions and practical implications, Journal of Business \& Industrial Marketing 29(3): 199-208. http://dx.doi.org/10.1108/JBIM-08-2012-0134

Churchill, G. A.; Ford, N. M.; Walker, O. C. 1974. Measuring the job satisfaction of industrial salesmen, Journal of Marketing Research 11(3): 254-260. http://dx.doi.org/10.2307/3151140

Darrat, M.; Amyx, D.; Bennett, R. 2010. An investigation into the effects of work-family conflict and job satisfaction on salesperson deviance, Journal of Personal Selling and Sales Management 30(3): 239-252. http://dx.doi.org/10.2753/PSS0885-3134300304

Deci, E. L.; Ryan, R. M. 2002. Handbook of self-determination research. Rochester, NY: University of Rochester Press.

Fatima, A.; Muhammad, Q.; Saqib, A. A.; Haider, A. 2012. A path model examining the relations among organizational injustice, counterproductive work behavior and job satisfaction, International Journal of Innovation, Management and Technology 3(6): 697-701.

Fornell, C.; Wernerfelt, B. 1987. Defensive marketing strategy by customer complaint management: a theoretical analysis, Journal of Marketing Research 24(4): 337-346.

http://dx.doi.org/10.2307/3151381

Hair Jr., J. F.; Black, W. C.; Babin, B. J.; Anderson, R. E.; Tatham, R. L. 2006. Multivariate data analysis. Upper Saddle River, NJ: Pearson Prentice Hall.

Harris, L. C.; Ogbonna, E. 2006. Service sabotage: a study of antecedents and consequences, Journal of the Academy of Marketing Science 34(4): 543-558.

http://dx.doi.org/10.1177/0092070306287324

Hartline, M. D.; Ferrell, O. C. 1996. The management of customer-contact service employees: an empirical investigation, The Journal of Marketing 60(4): 52-70. http://dx.doi.org/10.2307/1251901 
Henning-Thurau, T. 2004. Customer orientation of service employees: its impact on customer satisfaction, commitment, and retention, International Journal of Service Industry Management 15(5): 460-478. http://dx.doi.org/10.1108/09564230410564939

Heskett, J. L.; Schlesinger, L. A. 1994. Putting the service-profit chain to work, Harvard Business Review 72(2): 164-174.

Hoffman, K. D.; Ingram, T. N. 1992. Service provider job satisfaction and customer, Journal of Services Marketing 6(2): 68-78. http://dx.doi.org/10.1108/08876049210035872

Hofstede, G. H. 1984. Culture's consequences: international differences in work-related values. Beverley Hills, CA: Sage.

Huff, L.; Kelley, L. 2005. Is collectivism a liability? The impact of culture on organizational trust and customer orientation: a seven-nation study, Journal of Business Research 58(1): 96-102. http://dx.doi.org/10.1016/S0148-2963(02)00478-2

Hulin, C. L. 1991. Adaption, persistence, and commitment in organizations, in M. D. Dunnette, L. M. Hough. Handbook of industrial and organizational psychology, Vol. 2. $2^{\text {nd }}$ ed. Palo Alto, CA: Consulting Psychologists Press.

Jelinek, R.; Ahearne, M. 2006. The enemy within: examining salesperson deviance and its determinants, Journal of Personal Selling and Sales Management 26(4): 327-344.

http://dx.doi.org/10.2753/PSS0885-3134260401

Jelinek, R.; Ahearne, M. 2010. Be careful what you look for: the effect of trait competitiveness and long hours on salesperson deviance and whether meaningfulness of work matters, The Journal of Marketing Theory and Practice 18(4): 303-321.

http://dx.doi.org/10.2753/MTP1069-6679180401

Judge, T. A.; Locke, E. A.; Durham, C. C. 1997. The dispositional causes of job satisfaction: a core evaluations approach, Research in Organizational Behavior 19: 151-188.

http://dx.doi.org/10.1037/0021-9010.83.1.17

Korschun, D.; Bhattacharya, C. B.; Swain, S. D. 2014. Corporate social responsibility, customer orientation, and the job performance of frontline employees, Journal of Marketing 78(3): 20-37. http://dx.doi.org/10.1509/jm.11.0245

Litzky, B. E.; Eddleston, K. A.; Kidder, D. L. 2006. The good, the bad, and the misguided: how managers inadvertently encourage deviant behaviors, The Academy of Management Perspectives 20(1): 91-103. http://dx.doi.org/10.5465/AMP.2006.19873411

Locke, E. A. 1969. What is job satisfaction?, Organizational Behavior and Human Performance 4(4): 309-336. http://dx.doi.org/10.1016/0030-5073(69)90013-0

Malhotra, N. K. 2010. Marketing research: an applied orientation. Upper Saddle River, NJ: Pearson.

McCain, S. C.; Tsai, H.; Bellino, N. 2010. Organizational justice, employees' ethical behavior, and job satisfaction in the casino industry, International Journal of Contemporary Hospitality Management 22(7): 992-1009. http://dx.doi.org/10.1108/09596111011066644

Morris, J. H.; Sherman, J. D.; Mansfield, E. R. 1986. Failures to detect moderating effects with ordinary least squares-moderated multiple regression: some reasons and a remedy, Psychological Bulletin 99(2): 282-288. http://dx.doi.org/10.1037/0033-2909.99.2.282

Mount, M.; Ilies, R.; Johnson, E. 2006. Relationship of personality traits and counterproductive work behaviors: the mediating effects of job satisfaction, Personnel Psychology 59(3): 591-622. http://dx.doi.org/10.1111/j.1744-6570.2006.00048.x

Mulki, J. P.; Jaramillo, F.; Locander, W. B. 2006. Emotional exhaustion and organizational deviance: can the right job and a leader's style make a difference?, Journal of Business Research 59(12): 1222-1230. http://dx.doi.org/10.1016/j.jbusres.2006.09.001 
Organ, D. W.; Podsakoff, P. M.; MacKenzie, S. B. 2006. Organizational citizenship behavior: its nature, antecedents, and consequences. Thousand Oaks: Sage Publications.

Pallant, J. 2010. SPSS survival manual: a step by step guide to data analysis using SPSS. Open University Press.

Robinson, S. L.; Bennett, R. J. 1995. A typology of deviant workplace behaviors: a multidimensional scaling study, Academy of Management Journal 38(2): 555-572.

http://dx.doi.org/10.2307/256693

Saxe, R.; Weitz, B. A. 1982. The SOCO scale: a measure of the customer orientation of salespeople, Journal of Marketing Research 19(3): 343-351. http://dx.doi.org/10.2307/3151568

Swimberghe, K.; Jones, R. P.; Darrat, M. 2014. Deviant behavior in retail, when sales associates "Go Bad"! Examining the relationship between the work-family interface, job stress, and salesperson deviance, Journal of Retailing and Consumer Services 21(4): 424-431.

http://dx.doi.org/10.1016/j.jretconser.2014.03.001

Teddlie, C.; Yu, F. 2007. Mixed methods sampling a typology with examples, Journal of Mixed Methods Research 1(1): 77-100. http://dx.doi.org/10.1177/2345678906292430

Thomas, R. W.; Soutar, G. N.; Ryan, M. M. 2001. The selling orientation-customer orientation (SOCO) scale: a proposed short form, Journal of Personal Selling and Sales Management 14(1): 63-69. http://dx.doi.org/10.1080/08853134.2001.10754257

Yoo, J. J.; Flaherty, K.; Frankwick, G. L. 2014. The effect of communication practice on deviance among Korean salespeople: the mediating role of intrinsic motivation, Journal of Business Research 67(9): 1991-1999. http://dx.doi.org/10.1016/j.busres.2013.10.012

Yoo, J. J.; Frankwick, G. L. 2013. Exploring the impact of social undermining on salesperson deviance: an integrated model, Journal of Personal Selling and Sales Management 33 (1): 79-90. http://dx.doi.org/10.2753/PSS0885-3134330107

Joseph LO IACONO is a PhD Candidate at Griffith University and currently teaches in the Department of Marketing, Griffith University. He holds a Bachelor of Business and Masters of Marketing with Honours in Marketing. His research interests include internal marketing and services marketing.

Scott K. WEAVEN, Professor, is Deputy Director of Griffith University's Asia-Pacific Centre for Franchising Excellence and currently teaches in the Department of Marketing, Griffith University. His research interests include franchising and small business management and has been published in international journals including the Journal of the Academy of Marketing Science, Journal of Retailing, European Journal of Marketing, amongst others.

Deborah GRIFFIN, Doctor, teaches marketing at Griffith University. She holds a Bachelor of Arts with Honours in Marketing and a PhD in Marketing. Her research interests lie within the consumer behaviour and social marketing areas. She has published in the Journal of Consumer Behaviour, Journal of Nonprofit \& Public Sector Marketing, amongst others. 